\title{
Accidental poisoning in children: can we admit fewer children with safety?
}

\author{
J R Sibert, P A Routledge
}

Accidental poisoning, despite the impact of child resistant containers, remains a common problem. In England and Wales the Home Accident Surveillance System suggests that 36000 children presented to accident and emergency departments in 1986 (Department of Trade and Industry, 1988, personal communication). Nevertheless most of these children do not have serious symptoms ${ }^{1}$ and have either taken a relatively non-toxic substance or not enough of a toxic substance to cause problems. Nevertheless, a few children do die from accidental poisoning, ${ }^{2}$ and a few would die without expert medical care. Is it possible to avoid admitting children unnecessarily while still maintaining safety?

\section{Classifying poisons taken by children}

We suggest a way round this dilemma in the treatment of accidental poisoning is to classify the substance the child has taken into one of four categories: low toxicity, intermediate toxicity, potential toxicity, or uncertain toxicity. Children who have accidentally taken a substance of low toxicity can be sent home. Children who have accidentally taken a substance of intermediate toxicity can be observed for a short period in the accident and emergency department or paediatric ward. Many accident and emergency departments now have special areas for children where they can stay for periods of time up to a few hours. Alternatively most paediatric wards are able to accommodate children, who are not formally admitted, for short periods of time for observation. Children who have taken a substance with a potential for toxicity should be admitted for observation and treatment. The local poisons information centre should be contacted if there is any doubt concerning the toxicity of a substance or the treatment that is needed.

A suggested classification of substances children take accidentally (including medicines, household products, and plants) is shown in the table. The substances in this table are those most commonly taken by children accidentally and we have chosen them from information from the work of Craft et al, ${ }^{3}$ Sibert et al, ${ }^{4}$ and from inquiries to the Welsh National Poisons Unit.

Deliberate and non-accidental poisoning It is important to differentiate between children who have accidentally taken poisons and those who have either deliberately taken poisons or been poisoned deliberately. Accidental poisoning is a problem with toddlers with a mean age of 30 months. Children who have deliberately taken poison are usually much older than children who accidentally poison themselves and should be easily recognised. They need full psychiatric and social assessment and should be admitted to hospital. ${ }^{5}$ Children who have been deliberately poisoned by their parents need admission so that they can be fully assessed both medically and socially. ${ }^{6}$ They will also need referral under the local child abuse procedures.

\section{Preventing further accidents}

The parents of all children who present with accidental poisoning in childhood should be given advice regarding storage of medicines and household products. The health visitor should be contacted in all cases remembering that family psychosocial stress is often linked with accidental poisoning in childhood. ${ }^{7}$ There may be specific problems that need medical or social help.

\section{Accidental poisoning in childhood with} substances of low toxicity

Children who have taken substances of low toxicity can be allowed home after assessment. If there is doubt over what a child has taken a conservative approach should be taken. Emptying the stomach is not necessary in these cases.

\section{Which substances can be classified as of} low toxicity?

Antibiotics, with certain exceptions such as ciprofloxacin, sulphasalazine, and chloramphenicol, are of low toxicity if taken accidentally by children. Despite this children are not infrequently admitted to hospital with antibiotic 'poisoning'. This is not necessary. Similarly antacids, calamine, and zinc oxide do not cause serious symptoms if ingested by children. Oral contraceptives have a theoretical risk of breast enlargement and withdrawal vaginal bleeding if taken accidentally by children but this must be very rare and does not need treatment. Vitamin preparations are also non-toxic if ingested in children, however care must be taken to see that the preparation does not contain iron.

Children also take a number of household products accidentally. Many of are these are 
Guide to toxicity of substances taken in accidental child poisoning

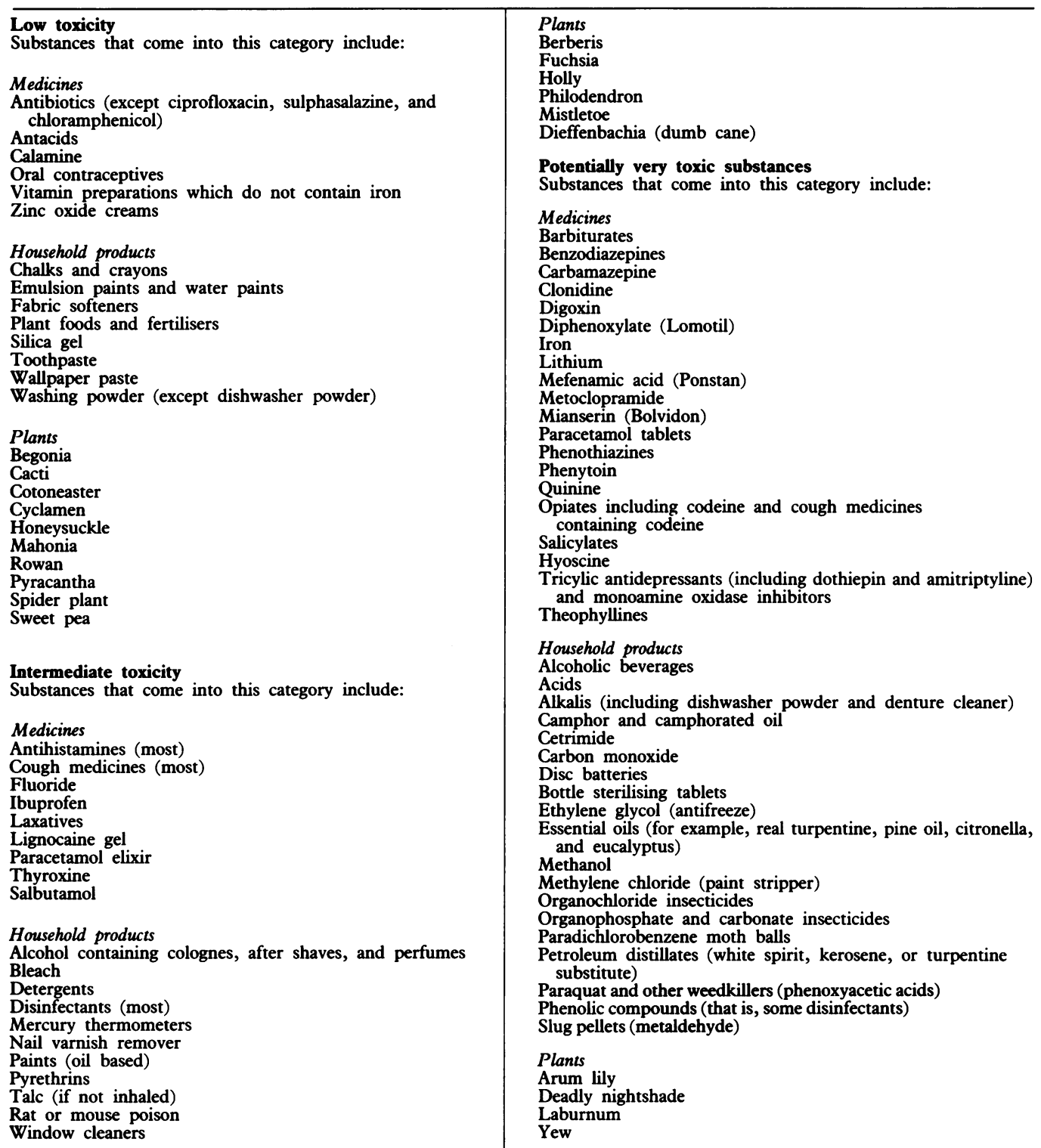

The table is reproduced with permission from 'Accidents, poisoning and sudden infant death syndrome' by JR Sibert and P Davies in Forfar and Ameil's Textbook of Paediatrics. 4th Ed. Edited by AGM Campbell and N McIntosh. Churchill Livingstone, Edinburgh (in press).

non-toxic ${ }^{3}$ and children who have ingested them can be sent home. Examples are chalks and crayons, emulsion paints and water paints, fabric softeners, plant foods and fertilisers, silica gel, toothpaste, wallpaper paste, and washing powder. The only problem with these substances is ensuring that the child has not taken a similar but more toxic substance-for example washing powder not dishwasher powder (which is caustic). There are also a number of plants children may take that are of low toxicity: begonia, cacti, cotoneaster, cyclamen, honeysuckle, mahonia, rowan, pyracantha, spider plant, and sweet pea. Again the only problem should be one of identification.

\section{Accidental poisoning in childhood with substances of intermediate toxicity}

Children who have taken substances of intermediate toxicity accidentally should be observed for a period in hospital (usually up to six hours) until one can be confident that important symptoms are not going to occur. If there are adverse factors, particularly social factors or if large quantities have been ingested, children should be admitted to hospital.

\section{Which substances can be regarded as of intermediate toxicity?}

ANTIHISTAMINES AND COUGH MEDICINES (MOST) Most antihistamine preparations and cough medicines do not cause serious symptoms in the quantities taken by children. There may be drowsiness and anticholinergic effects but these should be obvious after six hours' observation. Drowsiness should usually not need treatment. Those cough medicines based on codeine should be regarded as potentially toxic.

\section{FLUORIDE}

Children may ingest fluoride tablets or drops 
used to prevent tooth decay. Fluoride has a rapid action but is seldom toxic in the quantities taken by children. Symptoms include vomiting, nausea, and abdominal pain and should be obvious after six hours' observation.

\section{IBUPROFEN}

Ibuprofen and other non-steroidal antiinflammatory agents seem only seldom to cause symptoms when accidentally ingested by children. Symptoms include gastrointestinal irritation.

\section{LAXATIVES}

Serious symptoms after accidental ingestion of laxatives are rare. If diarrhoea occurs it usually occurs quickly and should be obvious after six hours' observation.

\section{LIGNOCAINE GEL}

Although local anaesthetics such as lignocaine are toxic in overdose causing convulsions, appreciable amounts of lignocaine gel are very seldom ingested accidentally by children.

\section{PARACETAMOL ELIXIR}

Paracetamol elixirs such as Calpol are sweet and sickly in large doses and serious accidental poisoning is very rare. There is hardly enough paracetamol in most small bottles of elixir to cause problems. If a child has taken a paracetamol elixir the stomach should be emptied using ipecacuanha. Blood concentrations should be checked four hours after the ingestion if more than $150 \mathrm{mg} / \mathrm{kg}$ has been taken. Treatment is only needed if the serum paracetamol concentration is above the recommended treatment line. ${ }^{8}$ In most cases children can be discharged after a period of observation.

\section{SALBUTAMOL}

Although salbutamol can cause peripheral vasodilation, hypokalaemia, muscle tremors, and agitation, serious symptoms are rare and should be obvious after six hours' observation.

ALCOHOL CONTAINING PERFUMES, COLOGNE, AND AFTER SHAVE

Craft $e t a l^{3}$ and Scherger $e t a l^{9}$ found no symptomatic cases in their series. Asymptomatic children can be allowed home after a short period of observation to make certain they do not become drowsy.

\section{BLEACH}

Accidental ingestion of household bleach causes many fewer problems than would be expected. Craft $e t$ al found no cases that had any serious symptoms in their series. ${ }^{3}$ Local lesions in the mouth can be treated symptomatically and should be obvious after a short period. In the few cases where there is doubt about the presence of an appreciable oesophageal problem endoscopy can be undertaken.
DETERGENTS (ANIONIC)

Anionic detergents such as hand dishwashing liquid and shampoo are only toxic in large doses. Craft $e t$ al found no serious cases in their series, ${ }^{3}$ although vomiting is said to occur in large doses. Observation for a period should be all that is needed in these cases.

\section{DISINFECTANTS (MOST)}

Craft et al found no serious cases in their series. ${ }^{3}$

NAIL VARNISH REMOVER (ACETONE)

Craft $e t$ al found no serious cases in their series. ${ }^{3}$ Nausea and vomiting may occur if large amounts are taken but children do not often take significant quantities. Observation for a period should be all that is needed in these cases.

\section{PAINTS (OIL BASED)}

Craft et al found no serious cases in their series. ${ }^{3}$ The only problems that occur, unless the paint has lead in it, are caused by the petroleum distillate base. The stomach should not be emptied. In practice children do not seem to take significant amounts.

\section{PYRETHRINS}

These insecticides are not usually a hazard if ingested or inhaled accidentally. The child should be observed for a short period.

\section{RAT OR MOUSE POISON}

The common ingredients of rat or mouse poison (warfarin or dichlorolose) are usually non-toxic in the doses taken by children. The exact type of poison should by identified by contacting the local poisons centre and in most cases the child can be sent home after a short period of observation.

If large amounts of warfarin are ingested vita$\min \mathrm{K}$ can be used but this is not needed in most cases. Craft $e t$ al found no serious cases in their series. ${ }^{3}$

TALC

Talc is only toxic if inhaled when it may cause retching and choking. Cases of accidental ingestion need to be observed only for a short period to make certain that appreciable aspiration did not occur.

\section{WINDOW CLEANERS}

Craft $e$ al found no serious cases in their series, ${ }^{3}$ and most types are non-toxic apart from the danger of aspiration. The exact type of cleaner should be identified through the poison's centre and in most cases the child can be sent home after a short period of observation.

PLANTS

Berberis, fuchsia, holly, philodendron, mistle- 
toe, dieffenbachia (dumb cane) all can theoretically cause problems if taken in excess, however they are unlikely to cause problems if ingested accidentally by children. Usually only small quantities are ingested and observation for a short period is all that is required.

\section{Accidental poisoning in childhood with} potentially very toxic substances

Children who have taken substances of potential toxicity should be admitted to hospital for observation and treatment. Although most children who accidentally ingest these substances come to no harm, there are clear potential problems with all the substances we have put on this list.

Accidental poisoning in childhood where there is uncertainty of toxicity

If there is any doubt about the toxicity of a substance a child may have taken, the local poison's information centre should be contacted day or night (see appendix).

Some children arrive in hospital having taken unknown tablets or household products. Often discussion with the poisons information service will help. If there is doubt the child should be admitted for observation.
Appendix: telephone numbers of national centres

London:

Guy's Hospital 0719555095 or 0716359191

Edinburgh:

Royal Infirmary

Cardiff:

Llandough Hospital

0222709901

Belfast:

Royal Victoria Infirmary $\quad 0232240503$

Dublin

0001379964

Birmingham

0215543801

Leeds

0532430715

Newcastle

1 Wiseman HM, Guest K, Murray VSG, Volans GN. Accidental poisoning in childhood: a multicentre study. Hum Toxicol 1987;6:293-314.

2 Craft AW. Circumstances surrounding deaths from accidental poisoning 1974-1980. Arch Dis Child 1983;58:544-6.

tal poisoning 1974-1980. Arch Dis Child 1983;58:544-6. childhood poisoning with household products. BMJ 1984;288:682.

4 Sibert JR, Clarke AJ, Mitchell MP. Improvements in child resistant containers. Arch Dis Child 1985;60:1155-7.

5 Taylor EA, Stanfield SA. Children who poison themselves. Br F Psychiatry 1984;145:127-35.

6 Rogers D, Tripp J, Bentovim A, Robinson A, Berry D Goulding $R$. Non-accidental poisoning: an extended syndrome of child abuse. $B M \mathcal{F} 1976 ; \mathrm{i}: 793-6$.

7 Sibert JR. Stress in families of children who have ingested poisons. BMF 1975; ii:87-9.

8 Rumack B, Matthew $H$. Acetaminophen poisoning and toxicity. Pediatrics 1975;55:871-6.

9 Scherger DL, Wruk KM, Kulig KW, Rumack BH. Ethyl alcohol containing cologne, perfume and after shave. Ingestions in children. Am 7 Dis Child 1988;142:630-2.

Routine urines

Most children seen at a hospital either as an inpatient or an outpatient have a dipstick urine test and many have urine microscopy. In a report from Memphis, Tennessee, Mitchell and Stapleton (Pediatrics 1990;86:345-9) question whether routine urine testing is worthwhile. Urine analyses (dipstick and microscopy) were performed on 732 patients who had no clinical problem for which urine analysis would be regarded as necessary. An abnormality was found in $20 \%$ of urines: $12 \%$ had pyuria, $9 \%$ haematuria, $4.5 \%$ glycosuria, and $4 \%$ proteinuria.

Although routine urine testing was allegedly mandatory hospital policy, in practice it was done on only $30 \%$ of children and when an abnormality was found it was usually ignored $(70 \%$ of abnormal results were not followed up). The only diagnoses made as a result of screening were of urinary infection in six patients. The authors conclude that routine urine analysis is costly and nonproductive. They have, however, shown that it gives a high yield of abnormal results but they have not been able to demonstrate the significance of those findings. Perhaps they should concentrate more on staff education than on test dismissal. If $70 \%$ of abnormal tests on my unit got ignored I don't think writing a paper about it would be the first thing to come to mind. 